\title{
Interactive effects of climate change and biodiversity loss on ecosystem functioning
}

\author{
Aliny P. F. Pires, ${ }^{1,2,3,7}$ Diane S. Srivastava, ${ }^{4}$ Nicholas A. C. Marino, ${ }^{1}$ A. Andrew M. MacDonald, ${ }^{4}$ \\ Marcos Paulo Figueiredo-Barros, ${ }^{5}$ and Vinicius F. Farjalla ${ }^{1,3,6}$ \\ ${ }^{1}$ Departamento de Ecologia, Instituto de Biologia, Universidade Federal do Rio de Janeiro, Rio de Janeiro, Rio de Janeiro, Brazil \\ ${ }^{2}$ Fundação Brasileira para o Desenvolvimento Sustentável, Rio de Janeiro, Rio de Janeiro, Brazil \\ ${ }^{3}$ Brazilian Research Network on Climate Change - Rede Clima, Instituto Nacional de Pesquisas Espaciais, \\ São José dos Campos, Sao Paulo, Brazil \\ ${ }^{4}$ Department of Zoology and Biodiversity Research Centre, University of British Columbia, 6270 University Boulevard, Vancouver, British \\ Columbia V6T1Z4, Canada \\ ${ }^{5}$ Núcleo em Ecologia e Desenvolvimento Socio-Ambiental de Macaé (NUPEM/UFRJ), Universidade Federal do \\ Rio de Janeiro, Macaé, Rio de Janeiro, Brazil \\ ${ }^{6}$ Laboratorio Internacional en Cambio Global-LINCGlobal, Sunnyvale, California, USA
}

\begin{abstract}
Climate change and biodiversity loss are expected to simultaneously affect ecosystems, however research on how each driver mediates the effect of the other has been limited in scope. The multiple stressor framework emphasizes non-additive effects, but biodiversity may also buffer the effects of climate change, and climate change may alter which mechanisms underlie biodiversity-function relationships. Here, we performed an experiment using tank bromeliad ecosystems to test the various ways that rainfall changes and litter diversity may jointly determine ecological processes. Litter diversity and rainfall changes interactively affected multiple functions, but how depends on the process measured. High litter diversity buffered the effects of altered rainfall on detritivore communities, evidence of insurance against impacts of climate change. Altered rainfall affected the mechanisms by which litter diversity influenced decomposition, reducing the importance of complementary attributes of species (complementarity effects), and resulting in an increasing dependence on the maintenance of specific species (dominance effects). Finally, altered rainfall conditions prevented litter diversity from fueling methanogenesis, because such changes in rainfall reduced microbial activity by $58 \%$. Together, these results demonstrate that the effects of climate change and biodiversity loss on ecosystems cannot be understood in isolation and interactions between these stressors can be multifaceted.
\end{abstract}

Key words: complementarity effects; decomposition; detritivores; dominance effects; global changes; insurance effects; litter diversity; rainfall manipulation; tank bromeliad ecosystems.

\section{INTRODUCTION}

Climate change and biodiversity loss are both expected to have profound effects on how food webs are structured and how ecosystems function. As both types of change are simultaneously affecting ecosystems (Hooper et al. 2012), a key question is whether their effects will be independent of each other. To date, this question has been primarily considered in the context of biodiversity stabilizing ecosystems against climatic stressors, such that biodiversity loss erodes the ability of ecosystems to withstand the effects of climate change. The rationale here is that even species that are functionally equivalent can differ in their tolerance of climatic stressors, insuring that ecosystem functions can be maintained in the face of climate change (Yachi and Loreau 1999, Eklöf et al. 2012, Pires et al. 2018). The high potential for such compensatory effects in diverse communities buffers such communities against change driven by climatic stressors. There is some empirical support for such insurance effects of biodiversity, for example, diverse grasslands are better able to remain productive following drought (Tilman

Manuscript received 18 September 2017; revised 22 January 2018; accepted 15 February 2018. Corresponding Editor: James T. Cronin.

${ }^{7}$ E-mail: alinypfpires@gmail.com
1996, Wang et al. 2007). Similarly, diverse microbial communities seem to be more stable and the processes they perform more resilient to changes in temperature (Bruder et al. 2011, Awasthi et al. 2014). These effects of biodiversity on stabilizing ecosystems against climate-induced changes consider the magnitude, but not the direction, of deviations from current conditions. This differs from the approach taken under a multiple-stressor framework, where the direction of change is important in assessing additivity of biodiversity and climate effects on ecosystem properties.

Despite substantial interest in how biodiversity could potentially mediate the effects of climate change (Eklöf et al. 2012), the converse process of how climate change could mediate the functional effects of biodiversity loss has largely only been examined for plant diversity and primary productivity (Craven et al. 2016). Specifically, climate change could alter the mechanisms by which biodiversity affects ecosystem functioning, and thereby influence the rates of these functions. The main mechanisms by which biodiversity affects ecosystem functions are frequently grouped into complementarity and dominance effects (Loreau and Hector 2001, Fox 2005). Complementarity effects act by niche differentiation, facilitation, and compensatory dynamics while dominance effects predict that diverse communities are more likely to contain functionally unique 
species that eventually come to dominate such communities (Fox 2005, Behl and Stibor 2015). The relative importance of complementarity and dominance mechanisms in driving biodiversity-function mechanisms can be quantified if there is information on species functioning when alone and in combination with other species. Climate change creates winners and losers in communities, such that only a subset of species is resistant to the climatic stressor (Amundrud and Srivastava 2015, Isbell et al. 2015). Indeed, classic insurance effects of biodiversity require variance in species response to stressors, with only the resistant species maintaining function. This leads to the expectation that selection effects will become increasingly important under climatic stress and complementary effects will diminish (Steudel et al. 2012). Although complementary effects diminish for litter decomposition under drought stress (Santonja et al. 2015), living plants show either no change (Craven et al. 2016) or the opposite pattern, with complementary effects (including facilitation) increasing under stress (Mulder et al. 2001, Steudel et al. 2011). The net effect of climate change on the magnitude of biodiversity - ecosystem functions relationships will depend on the combined effect of changes in complementarity and dominance effects.

In this study, we use tank bromeliad ecosystems to test experimentally the interactive effects of climate change and biodiversity on the stability, mechanisms and additivity of ecological processes. Tank bromeliads have been increasingly used as model ecosystems to test many ecological hypotheses (Farjalla et al. 2012, 2016, Pires et al. 2016, 2017, Marino et al. 2017). These miniature aquatic ecosystems are fueled by inputs of litter from surrounding vegetation and supported by impounding of rainfall by bromeliad leaves (Pires et al. 2016). Litter is the main source of energy for the invertebrates and microbes that colonize this ecosystem and its decomposition drives several processes in tank bromeliad ecosystems (Fig. 1). We created a gradient in litter diversity consisting of all combinations of the litter of three plant species from our field site. Then we simulated climate change based on two of the main predictions for precipitation on the Atlantic coast of South America: an increase in the temporal clustering of rainfall and an increase in the occurrence of extreme rainfall events (Marengo et al. 2010). We focus here on rainfall changes as it is expected that it will have stronger effects on ecosystem functioning than temperature increases in tropical regions (IPCC 2014). We measured as responses the abundance and richness of the decomposer community, rates of litter decomposition, and methane concentration in the water, as these variables represent some of the most important stocks and fluxes in the tank bromeliad ecosystems (Srivastava 2006, Martinson et al. 2010, Pires et al. 2016).

In bromeliads, a number of important processes are fueled by litter (Fig. 1). When fresh litter falls into a bromeliad, it is rapidly colonized by aquatic bacteria and fungi that begin to enzymatically breakdown organic compounds. This microbial conditioning increases the nutritive value and digestibility of the litter, and is an important prerequisite for processing by invertebrate detritivores (Leroy et al. 2017). Invertebrates actively choose which bromeliads to colonize, based on cues including drought risk and water chemistry (Amundrud and Srivastava 2015, Hammill et al. 2015).
Under conditions of high microbial production and continuous water, anoxic conditions develop and permit methanogenesis (Altor and Mitsch 2008, Martinson et al. 2010). All of these processes are potentially affected both by the temporal patterning of rainfall and by litter diversity (Bruder et al. 2011, Santonja et al. 2015). Bromeliads dry out if there is a long continuous period without rain, potentially disrupting microbial conditioning, dissuading invertebrates from colonizing the bromeliad, and preventing the anoxic conditions needed for methanogenesis (Brandt et al. 2015). Litter species differ in their palatability and nutritive quality, such that litter diversity may affect decomposition though a combination of complementarity (e.g., litters may provide complementary nutrients) and dominance (e.g., presence of a palatable species) type mechanisms (Hoorens et al. 2003, Santonja et al. 2015). When litter diversity increases decomposition, methanogenesis should also increase.

We, therefore, predict that the effects of rainfall and litter diversity on the bromeliad system will show the following interdependencies (Fig. 1; inserted panels). We predict that (1) litter diversity will reduce the sensitivity of the bromeliad ecosystem to altered rainfall. For example, if litter types differ in their optimal rainfall distribution for decomposition, then bromeliads that contain multiple litter types will more likely to be able to maintain ambient levels of decomposition, and therefore detritivore density, under altered rainfall conditions (Kominoski et al. 2009, Bruder et al. 2011, Santonja et al. 2015). We also predict that (2) altered rainfall will shift the mechanisms underlying the litter diversity-decomposition relationship from complementarity to dominance. If, under altered rainfall conditions, only one of the litter species is effectively conditioned by microbes, then effects of litter diversity on decomposition will depend increasingly on the presence of this species: a dominance effect (van Meeteren et al. 2008, Duarte et al. 2009). Finally, we predict that (3) altered rainfall will suppress the positive effects of litter diversity on the magnitude of ecosystem responses (a non-additive effect). This could occur in several ways. If less frequent rainfall slows the microbial conditioning of some litter species (Jentsch et al. 2011, Santonja et al. 2015, Marino et al. 2017), then litter diversity-decomposition relationships may weaken due to the diminishing contribution of complementarity effects. This could have cascading effects on ecosystem processes driven by decomposition, such as detritivore and microbial productivity (Louca et al. 2016, 2017). Second, if rainfall change resulted in an increased prevalence of drought, there may not be time for the processes underlying litter diversity-function relationships to develop. For example, drought may disrupt the development of anoxic conditions and therefore methane production (Brandt et al. 2015).

\section{Material And Methods}

\section{Model ecosystem and experimental area}

We experimentally manipulated the water and litter inputs for tank bromeliads, all species of Neoregelia cruenta (Graham) L. B. Smith. We performed the field experiment in an open restinga area at Parque Nacional da Restinga de Jurubatiba, Rio de Janeiro, Brazil $\left(22^{\circ} 14^{\prime} \mathrm{S}, 41^{\circ} 33^{\prime} \mathrm{W}\right)$. The 


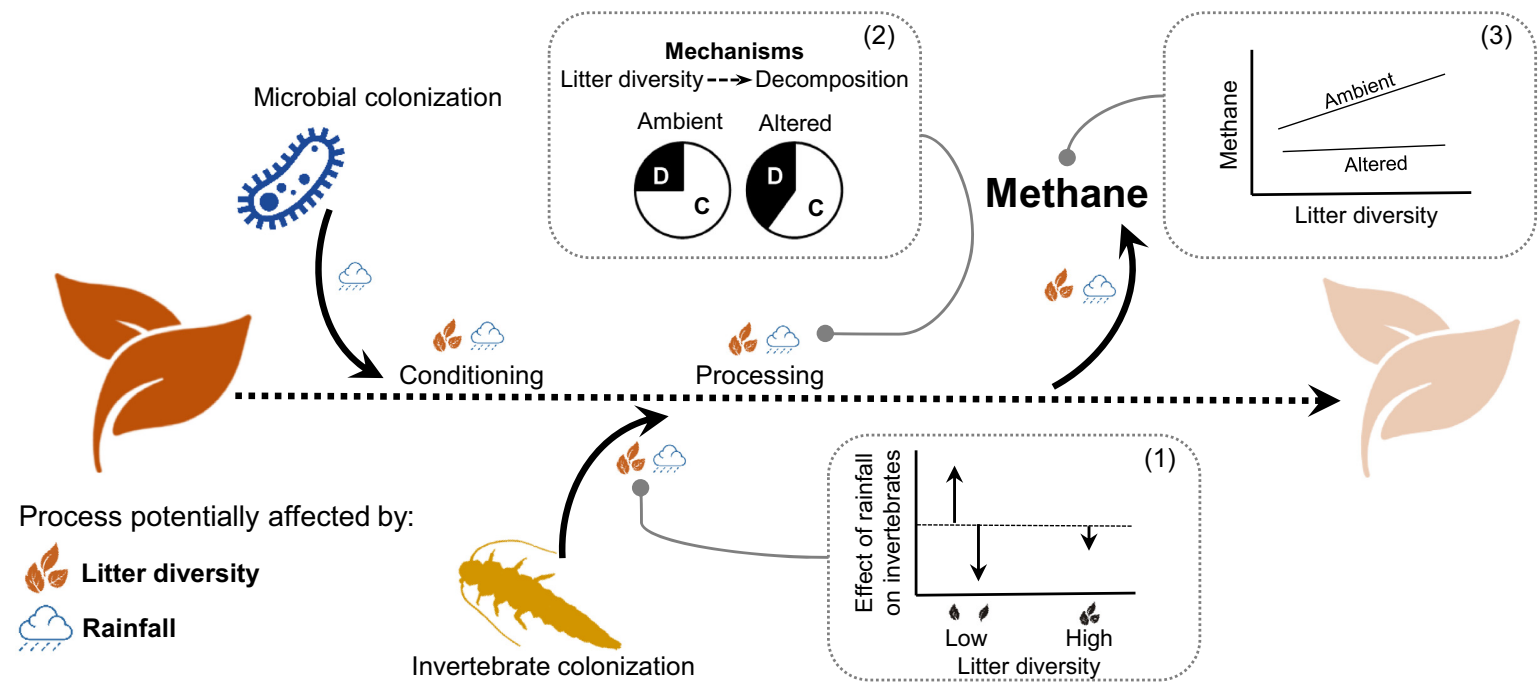

FIG. 1. Potential effects of changes in litter diversity and rainfall scenarios on detritus-fueled processes in tank bromeliads. In the main diagram, leaf litter entering the bromeliad (large brown leaf) is followed through time (dashed horizontal arrow) as it is colonized and conditioned by microbes and then processed by invertebrate detritivores, resulting in decomposition (large light-brown leaf) and release of methane, under anoxic conditions. Many of these processes are affected by the temporal distribution of rainfall and litter diversity, as indicated by icons. The inserted plots reveal three particular ways in which rainfall and litter diversity may interactively affect a process: (1) detritivores, for example, may be more sensitive (high absolute magnitude of change, regardless of direction) to altered rainfall at low litter diversity than high litter diversity; (2) shifts in rainfall may change the relative of importance of complementarity (C) and dominance (D) mechanisms underlying effects of litter diversity on decomposition; (3) there may be non-additive effects of altered rainfall and litter diversity on ecosystem functions, illustrated here as methanogenesis requiring both ambient rainfall and high litter diversity.

restinga vegetation at our site is a dune-based habitat, with patches of shrubby vegetation where the tank bromeliad Neoregelia cruenta is particularly abundant (Cogliatti-Carvalho et al. 2001). Tank bromeliads contain numerous species of aquatic invertebrates, mainly detritivores (Pires et al. 2016) that consume the fallen litter from the surrounding vegetation. Litter, especially tough and waxy species, needs to be microbially conditioned before detritivorous invertebrates can consume it. When microbial activity creates anoxic conditions, bromeliads can be appreciable sources of methane (Martinson et al. 2010, Louca et al. 2017).

\section{Experimental design}

We used a full-factorial design, composed of five rainfall scenarios crossed with all combinations of three litter species (seven litter combinations, including all one-, two- and three-species combinations), with five replicates. Rainfall scenarios were established based on precipitation projections for southeastern Brazil for the second half of this century (2071-2100), which includes increased temporal clustering of rainfall and an increase in the occurrence of extreme rainfall events, but no changes on the total amount of rain in the rainy season (Marengo et al. 2010). Similar changes are expected in other tropical ecosystems (IPCC 2014). An ambient scenario was established based on the daily rainfall pattern over the rainy season (November-February) during nine years for which meteorological data were collected at our field site (1997-2005). This ambient scenario had a rainfall event of $25 \mathrm{~mm}$ every $7 \mathrm{~d}$ (Fig. 2). Our medium clustering (MC) scenario had two consecutive days with rain, each with the same $25 \mathrm{~mm}$ of rainfall as the ambient scenario, whereas the high clustering (HC) scenario had four consecutive days of rain with the same $25 \mathrm{~mm}$ of rain falling on each of these four days (Fig. 2). The medium amplitude (MA) scenario had twice the ambient rainfall in one day (i.e., $50 \mathrm{~mm}$ ), whereas the high amplitude (HA) scenario had four times the ambient rainfall in one day (i.e., $100 \mathrm{~mm}$, Fig. 2). As we intentionally constrained our rainfall manipulations to have equivalent total amounts of rain, each altered scenario necessarily altered several parameters simultaneously. For example, increases in the occurrence of extreme rainfall events necessarily resulted in more consecutive days without rain. However, our design, in which the number of consecutive days without rain is similar between $\mathrm{MC}$ and $\mathrm{MA}$, and again between $\mathrm{HC}$ and $\mathrm{HA}$, at least partially accounted for these covariances. If the number of consecutive days without rain was most important, then a likely response would be Ambient $<\mathrm{MC}=\mathrm{MA}<\mathrm{HC}=\mathrm{HA}$, whereas if the occurrence of high amplitude, extreme events was most important, we would expect a response resembling Ambient $=\mathrm{MC}=\mathrm{HC}<\mathrm{MA}<\mathrm{HA}$.

The litter species used in this experiment were the most common representatives at the field site of three different photosynthetic strategies $\left(\mathrm{C}_{3}\right.$, Eugenia uniflora; $\mathrm{C}_{4}$, Cyperus sp.; and CAM, Clusia hilariana). We used all one-, two-, and three-species combinations between these three species, creating seven litter treatments. Litter was collected on site, washed and dried at $60^{\circ} \mathrm{C}$ until its mass stabilized. All bromeliads were dug up and washed to remove existing detritivores and litter, in order to standardize initial conditions. Bromeliad size is a strong determinant of bromeliad water dynamics (Zotz and Thomas 1999, Marino et al. 2017), so we controlled for bromeliad size in several ways: first, we chose bromeliads of approximately $30 \mathrm{~cm}$ in diameter; second, we ensured that any residual variation in size 


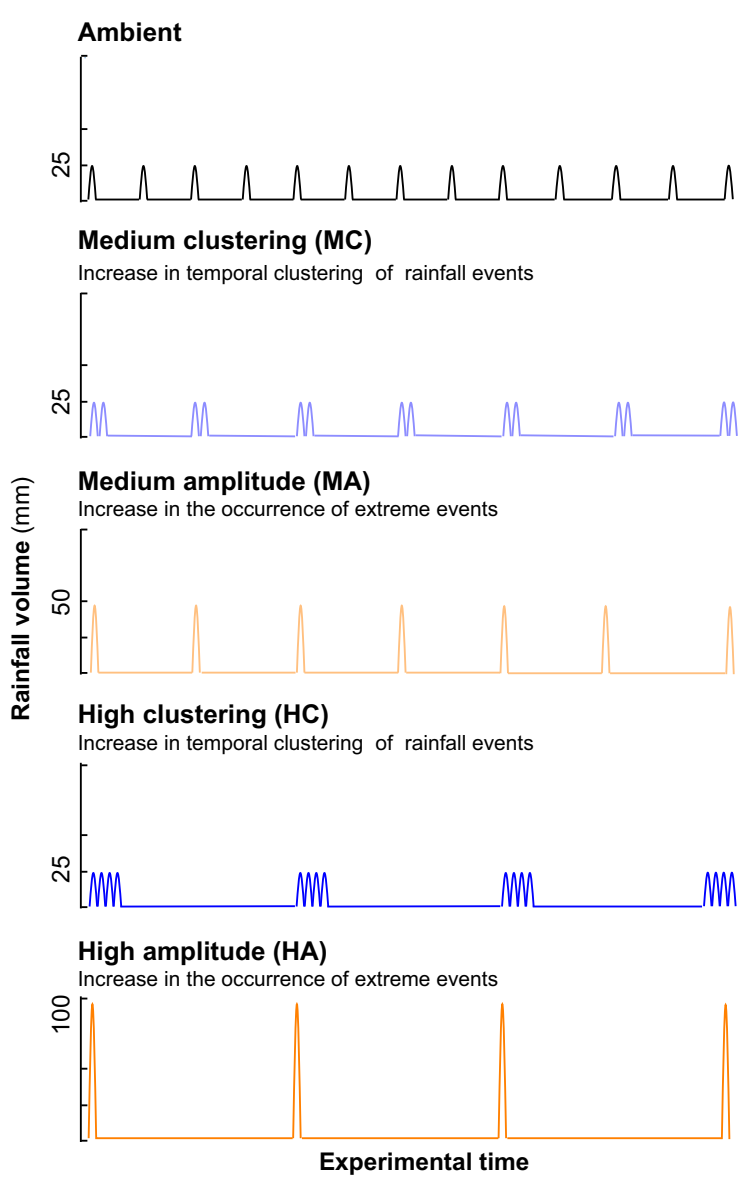

FIG. 2. Rainfall scenarios were established based on ambient conditions for the period 1997-2005 and predictions for Southeast Brazil in 2071-2100 and applied experimentally to bromeliads. An ambient scenario was altered by either increasing in the temporal clustering of rainfall (to medium $[\mathrm{MC}]$ or high $[\mathrm{HC}]$ amounts) or increasing the amplitude of extreme events (to medium [MA] or high [HA] amounts) without changing the total amount of rain over the experimental period.

was evenly distributed among treatments; and third, we measured the maximum volume of each bromeliad and used it as a covariate in statistical analyses. Bromeliads were replanted in the restinga in a spatially randomized arrangement. Each bromeliad received a total of $1.2 \mathrm{~g}$ of litter of the appropriate litter combination, in a substitutive design. We kept bromeliads water-filled at the field site for 3 months before the start of the experiment to allow macroinvertebrate community assembly (incubation period). In addition to these experimental bromeliads, we included, as a control, an extra 35 bromeliads assembled identically those in the main experiment (seven litter combinations, five replicates). These bromeliads were destructively sampled at the end of the assembly period to determine if litter diversity affected response variables during this assembly period. No response variable differed amongst the litter diversity treatments (for all response variables, $P>0.17$ ). After the assembly period, each bromeliad was covered individually with a transparent shelter, which allowed for light penetration and macroinvertebrate colonization but prevented natural inputs of rain. The rainfall scenarios were simulated experimentally for
3 months (rainy season,) by adding mineral water to each bromeliad using a watering can, according to the specific rainfall scenario (Fig. 2).

\section{Analytical procedures}

Methane concentration in bromeliad-held water was sampled monthly by slowly siphoning the undisturbed water after $5 \mathrm{~d}$ of the last rainfall event for three months $(95,125$, and $155 \mathrm{~d}$ after the experimental set up). Methane sampling was restricted to the rainfall manipulation period and we postponed three months (incubation period) for the first sampling to allow the re-establishment of the biological process after bromeliad manipulation (Brandt et al. 2015). In the end of the experiment, water was siphoned from bromeliad leaves to analyze bacterial production (Haubrich et al. 2009, Louca et al. 2017). Bacterial production was evaluated through the incorporation of ${ }^{3} \mathrm{H}$-leucine into bacterial cells. In the field, water samples $(1.2 \mathrm{~mL})$ were incubated in the dark for $45 \mathrm{~min}$ in $2.0 \mathrm{~mL}$ Eppendorf tubes containing $20 \mathrm{nmol} / \mathrm{L}$ of ${ }^{3} \mathrm{H}$-leucine (final concentration) at in situ temperature and the incorporation interrupted by $90 \mu \mathrm{L}$ of formol PA. Radioactivity was measured by a Liquid Scintillation System (Beckman LS-5600, Beckman Coulter, Inc., Analytical Instrument Systems Development Center, Fullerton, CA, USA) following procedures previously described for tank bromeliad ecosystems (Haubrich et al. 2009).

Aquatic macroinvertebrates were collected from the siphoned water as well as by leaf-by-leaf bromeliad dissection and washing. Macroinvertebrates were identified to species, where possible, and morphospecies otherwise, as in previous studies (Pires et al. 2016). Litter was collected and separated into species. Litter was dried at $60^{\circ} \mathrm{C}$ until its mass stabilized. Decomposition was quantified as the total loss of dry litter mass. We also measured the maximum volume of each bromeliad by filling the intact plant with water until its capacity was reached (Pires et al. 2017).

\section{Data analysis}

We examined three distinct ways in which litter diversity and rainfall scenario jointly affect aquatic ecosystems: the effect of diversity in buffering ecosystems against rainfall perturbations, the effect of rainfall on mechanisms underlying diversity-function relationships, and the interactions between diversity and rainfall on the magnitude of ecosystem stocks and fluxes. To assess the potential buffering effects of litter diversity on ecosystem functions, we developed a metric of sensitivity to rainfall change and assessed the relationship of this metric to litter diversity using a randomization approach. Specifically, we used as a metric of sensitivity the squared difference of a response variable in a particular litter mixture under an altered rainfall scenario (mean, based on $n=5$ ) from that in the same litter mixture but ambient conditions (mean, based on $n=5$ ). We then regressed this metric of sensitivity against litter diversity. We used a resampling method to generate bootstrap confidence intervals for this slope: we repeated the above calculation of the slope, but this time by randomly selecting, with replacement, the two sets of five replicates from all data for the 
given litter mixture irrespective of rainfall treatment. We then repeated the randomization steps 1,000 times to generate $95 \%$ confidence intervals for the slope. If the slope of this regression was negative, we concluded that increasing litter diversity reduces the effect of rainfall changes on the response variable, which represents a stabilizing effect.

To assess the effect of rainfall on mechanisms underlying diversity-function relationships, we first partitioned the effect of diversity on decomposition using a tripartite modification of the Price equation (Fox 2005). In proposing this tripartite partitioning for biodiversity-function effects, Fox (2005) argued that the dominance effect (DE) was most analogous to the natural selection term of the original Price equation, even though a previous partitioning method based on the Price equation had summed TDCE (trait-dependent complementarity effect) with DE to create a "selection effect" (Loreau and Hector 2001). We opted to follow Fox's reasoning, and thus in our analysis combine TICE (traitindependent complementarity effect) and TDCE to create a total complementarity effect (TCE), distinct from DE. In actuality, it matters little to our conclusions whether the Fox (2005) tripartite or Loreau and Hector (2001) bipartite method are followed, as TDCE is relatively minor in magnitude. Note that we were able to use tripartite partitioning as we quantified separately the loss of dry mass for each litter species in each rainfall scenario, and there are biologically plausible interpretations of complementarity and dominance for decomposition (for more details about the definitions and calculations of these mechanisms, see Appendix S1). We compared how TCE and DE values differed among rainfall scenarios with generalized linear models (GLMs) and we verified the importance of the TCE and $\mathrm{DE}$ in each rainfall scenario by using a one-sample $t$ test that compares the TCE and DE values to zero.

Finally, to examine potential interactions between diversity and rainfall on the magnitude of ecosystem stocks and fluxes, we used generalized linear models (GLMs) to analyze effects on litter decomposition, measures of the macroinvertebrate community, and bacterial production, and generalized mixed-effect models to analyze effects on $\mathrm{CH}_{4}$ concentration with time as a random factor nested with bromeliad identity. For all fixed-effects models, we used bromeliad maximum volume at the end of the experiment as a covariate, since bromeliad size directly determines how rainfall affects the depth of standing water within bromeliad axils (Marino et al. 2017). All models were also performed using litter identity as a covariate, but the inclusion of this variable did not qualitatively affect the results. Response variables were transformed as necessary to conform to the model assumption about residual distributions. We carried out the sensitivity analysis and GLMs with base functions in R v. 3.2.2 and the GLMM with the lme package (R Development Core Team 2015). We performed the one-sample $t$-test and graphs by using GraphPad Prism software v. 5.0 (GraphPad Software, La Jolla, CA, USA).

\section{RESULTS}

We found that litter diversity and rainfall scenario jointly affected aquatic ecosystems in the following ways: litter diversity buffered detritivore communities from rainfall perturbations; rainfall changed the mechanisms underlying litter diversity-decomposition relationships, and interactions between diversity and rainfall affected the magnitude of methane emissions. However, no single response variable showed all of these different types of interactive effects.

We observed that litter diversity was able to buffer the effects of rainfall changes on the detritivore community. Specifically, litter diversity reduced the sensitivity of detritivore richness to rainfall change under all altered scenarios (MC, slope $-3.457, \quad P=0.024 ;$ MA, slope -4.957 , $P=0.001 ; \mathrm{HC}$, slope $-3.14, P=0.014$; and HA, slope $-4.31, P=0.004$; bootstrapped sensitivity-diversity relationship for slope $<0$; Fig. 3a), and the sensitivity of detritivore abundance to the effects of MA and HA rainfall scenarios (MA, slope $-5359, P=0.026$; HA, slope -5637 , $P=0.044$; Fig. 3b). These buffering effects of litter diversity were associated with differential effects of litter identity on the detritivore community under altered rainfall. For example, the response of detritivore richness to rainfall depended on litter species (GLM, litter species $\times$ rainfall changes: $\left.F_{8,58}=2.52, P=0.019\right)$. Similarly, detritivore abundance responded differently to rainfall shifts depending on the underlying litter species (Fig. 3c). The highest detritivore abundances in E. uniflora litter monocultures occurred under ambient rainfall, whereas the highest detritivore abundances in Cyperus sp. litter monocultures and C. hilariana litter monocultures occurred, respectively, under moderate (MC and MA rainfall scenarios) and under all but moderate rainfall scenarios (Fig. 3c). These buffering effects of litter diversity on response to rainfall were limited to the detritivore community; we did not observe similar buffering effects on decomposition, bacterial production or methane concentration in any altered rainfall scenarios (For all response variable and rainfall scenarios, $P>0.113$; see Appendix S1: Table S1).

We also discovered that rainfall changed the mechanisms underlying litter diversity-decomposition relationships. In most rainfall scenarios, complementarity effects were prevalent (Fig. 4a), with most of this complementarity affect due to trait-dependent complementarity (TDCE; Appendix S1: Fig. S1). However, the magnitude of the complementarity effect differed among rainfall scenarios (GLM, $F_{4,95}=4.391, P=0.002$ ), with large positive complementarity effects in ambient (one-sample $t$ test, $0.086 \pm 0.03$ (Mean $\pm \mathrm{SE}$ ), $P=0.016$; Fig. 4a), MA (one-sample $t$ test, $0.185 \pm 0.03, P<0.0001$; Fig. 4a) and HC rainfall scenarios (one-sample $t$ test, $0.085 \pm 0.03, P=0.013$; Fig. 4a), and insignificant positive effects in the other rainfall scenarios. In terms of pairwise comparisons, total complementarity effects were higher under MA than MC and HA rainfall scenarios (Tukey HSD post-hoc test, Fig. 4, Appendix S1: Table S2). Dominance effects also differed in both magnitude and sign between rainfall scenarios (GLM, $\left.F_{4,95}=3.58, P=0.009\right)$, with dominance insignificant in ambient and clustered rainfall scenarios, negative in the MA rainfall scenario (one-sample $t$ test, $-0.030 \pm 0.008$, $P<0.001$; Fig. 4b) and switching to positive in the HA rainfall scenario (one-sample $t$ test, $0.010 \pm 0.004, P=0.023$; Fig. 4b). Dominance effects could be linked to particular litter species. Under MA rainfall, $C$. hilariana litter species 
a) Detritivore richness

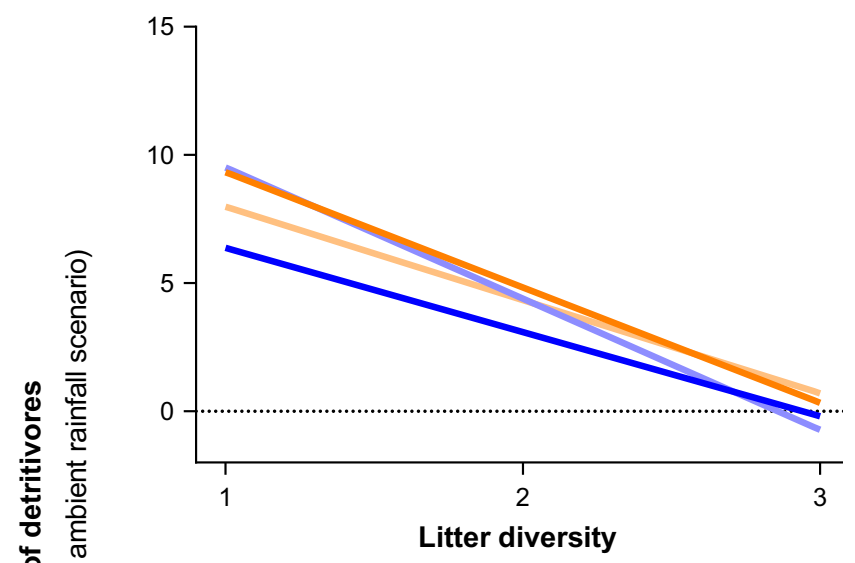

b) Detritivore abundance

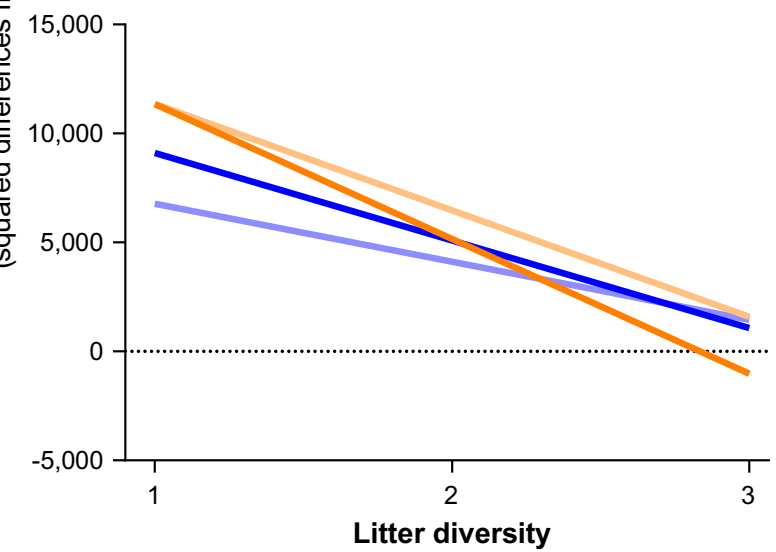

C

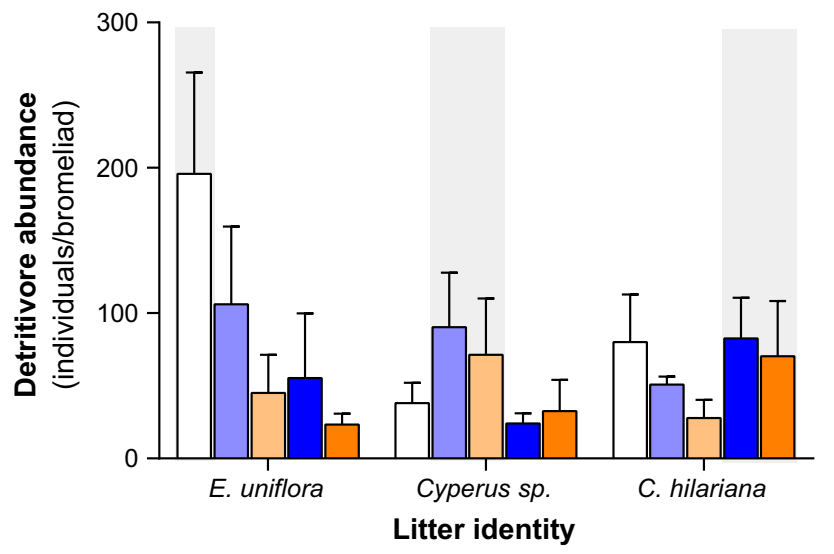

Rainfall scenario

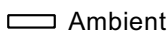

$\square \mathrm{MC}$

$\square \mathrm{MA}$

$\mathrm{HC}$

ए $\mathrm{HA}$

FIG. 3. Litter diversity reduces the sensitivity of (a) detritivore richness and (b) abundance to altered rainfall. The sensitivity of a response variable to a particular rainfall scenario was quantified as the squared difference between the ambient and altered rainfall scenarios and was averaged for each litter combination before calculating the regression lines shown. The significance of each regression slope was quantified using a bootstrap procedure. Negative slopes indicate stabilizing effects of litter diversity on response variables, indicative of a biodiversity insurance effect. (c) The effects of rainfall scenario on detritivore density differed between the three litter monocultures: Eugenia uniflora, Cyperus sp., and Clusia hilariana (mean \pm SE). For statistical details, see Appendix S1: Table S2.

depressed decomposition in mixtures (GLM, $F_{1,95}=71.09$, $P<0.001)$ whereas under HA rainfall, E. uniflora litter increased decomposition in mixtures $(E$. uniflora presence $\times$ HA rainfall scenario, GLM; $\left.F_{1,31}=13.49, P<0.001\right)$.

Finally, we asked if diversity and rainfall interacted to affect the magnitude of ecosystem stocks and fluxes. We observed a strong interaction between the effects of litter diversity and rainfall changes on methane concentration $\left(\right.$ GLMM $, F_{4,500}=3.38, P=0.009$; Fig. 5a, Appendix S1: Table S3). Specifically, litter diversity positively affected methane concentration in ambient rainfall conditions but this effect of diversity disappears in altered rainfall scenarios 

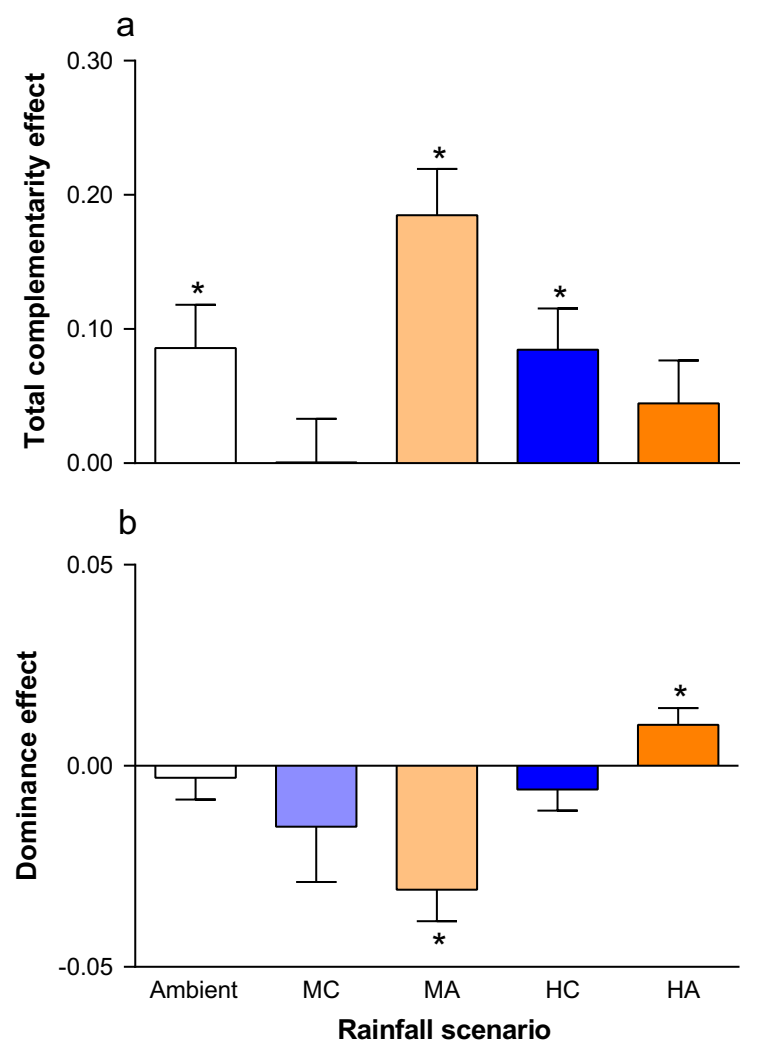

FIG. 4. The main mechanisms by which litter diversity affected decomposition depended on rainfall scenario. (a) Total complementarity and (b) dominance effects (mean $\pm \mathrm{SE}$, based on four litter combinations with $n=5$ ) were calculated based on a tripartite model (Fox 2005). Total complementarity effects were calculated by summing trait-dependent and trait-independent complementarity effects, which are presented separately in Appendix S1: Fig. S1. *Denotes significant differences from zero $(P \leq 0.05)$.

(Fig. 5a). Although no other response variables showed an interaction between litter diversity and rainfall in terms of magnitude, both bacterial production and decomposition were affected by one of these drivers. Rainfall changes significantly decreased bacterial production in tank bromeliad ecosystems $\left(\mathrm{GLM}, \quad F_{4,165}=4.46, \quad P=0.002 ; \quad\right.$ Fig. $5 \mathrm{~b}$, Appendix S1: Table S3). In the HA rainfall scenario, bacterial production was $58 \%$ lower than in ambient rainfall conditions (Fig. 5b). Bacterial production was unaffected by litter diversity (GLM, $F_{1,169}=0.02, \quad P=0.895$; Appendix S1: Table S3), the interaction between litter diversity and rainfall scenario (GLM, $F_{4,161}=1.86, P=0.120$; Appendix S1: Table S3) and the covariate of bromeliad size (GLM, $F_{1,170}=2.81, P=0.096$; Appendix S1: Table S3). By contrast, decomposition was positively affected by litter diversity (GLM, $F_{1,169}=5.18, \quad P=0.024 ; \quad$ Fig. $\quad 5$ c, Appendix S1: Table S3) and the three litter species differed substantially in their palatability to macroinvertebrates (E. uniflora $>$ Cyperus sp. $>$ C. hilariana; Appendix S1: Fig. S2; GLM, $\left.F_{2,70}=51.84, P<0.001\right)$. However, decomposition was insensitive to changes in rainfall (GLM, $F_{4,165}=0.90, P=0.464$; Appendix S1: Table S3), the interaction between rainfall and litter diversity (GLM, $F_{4,161}=0.25, \quad P=0.918 ;$ Appendix S1: Table S3) and
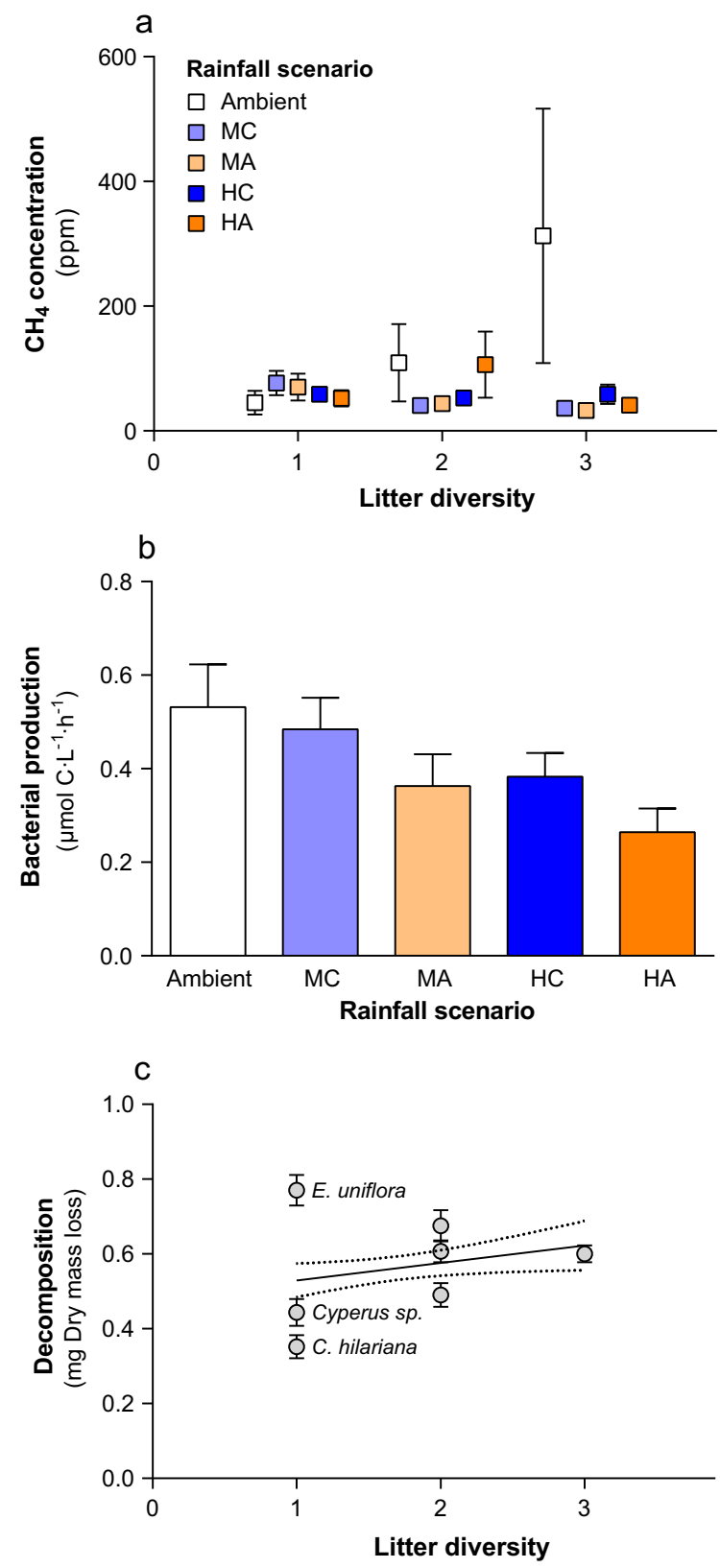

FIG. 5. Effects of rainfall scenario and litter diversity on methane concentration, microbial activity, and decomposition, respectively. (a) Methane concentration (mean \pm SE) in bromeliadheld water increased with litter diversity only under ambient rainfall conditions. (b) Bacterial production (mean $+\mathrm{SE}$ ) decreased as rainfall events become more clustered or of higher amplitude compared to ambient conditions. (c) Litter decomposition increased with litter diversity, on average (lines are slope and $95 \% \mathrm{CI}$ ), although there are large differences in the decomposition rates of litter species in monoculture. For details of statistical tests, see Appendix S1: Table S1.

bromeliad size (GLM, $F_{1,170}=0.81, P=0.368$; Appendix S1: Table S3).

\section{Discussion}

Climate change and biodiversity loss are the major drivers of global change but their combined effects are still 
underexplored in the ecological literature. We simulated climate change and biodiversity loss in tank bromeliad ecosystems and demonstrated that maintaining biodiversity can decrease ecosystem sensitivity to climate change, that climate change can switch the mechanisms underlying biodiversity-function relationships, and that climate change and biodiversity loss can have antagonistic effects on ecosystem functioning. There are therefore interactive effects between climate change and biodiversity loss on this tropical ecosystem, but such interactive effects were limited to specific processes.

Litter diversity stabilized the detritivore community against the effects of predicted rainfall changes in our field site, consistent with an insurance effect (Yachi and Loreau 1999). This insurance effect is likely due to the differential response of detritivores to specific litter species in each rainfall scenario. Detritivore abundance increased on Cyperus sp. litter after medium but not high changes in rainfall, increased on $C$. hilariana litter after high but not medium changes in rainfall, and decreased on E. uniflora litter for all altered rainfall scenarios. Because of statistical averaging of these litter-specific patterns, mixtures of litter species tended to show minimal differences in detritivore abundance and richness between rainfall scenarios.

Given that $E$. uniflora litter was always the most palatable of the three species, based on mass loss in the monocultures, it may seem surprising that detritivores did not always choose bromeliads with this litter species. Under ambient conditions, detritivore abundance did follow the rank order of the palatability of the litter species (E. uniflora $>$ Cyperus sp. $>C$. hilariana). However, under altered rainfall, it may be that litter interferes with oviposition cues. For example, C. hilariana litter is dense and sinks, revealing even small quantities of standing water, whereas E. uniflora litter floats, obscuring all but large quantities of standing water (Pires et al. 2017). Insects are thought to choose phytotelmata based on desiccation probability (Amundrud and Srivastava 2015) so it may be that differences in the buoyancy of litter led to misleading oviposition cues. Thus, we hypothesize that only high litter diversity allowed detritivores to encounter palatable litter despite effects of rainfall on oviposition cues. A recent bromeliad study also suggests that changes in rainfall can also lead to misleading oviposition cues in terms of predator kairomones (Marino et al. 2017), pointing to complex and largely unexpected effects of rainfall on insect behavior.

Rainfall changes also led to a fundamental switch in the underlying process by which litter diversity promoted decomposition. In this study, as in several previous studies, litter diversity was associated with increased total decomposition (Gessner et al. 2010). Relationships between biodiversity and ecosystem function can usefully be partitioned into two broad subclasses of patterns, often interpreted to reflect different ecological processes (Hillebrand and Matthiessen 2009). Complementarity can arise from functional differences between species in ecological niches (Fox 2005). Dominance effects occur when one or a few species, with inherently higher or lower functional rates, alter net rates of functioning in mixtures (Fox 2005). In our system, complementarity was the main process underlying diversity- decomposition relationships under ambient conditions, when detritivore abundance followed the palatability of the litter species. Although our experiment does not explore the reasons for this complementarity, in other systems litter mixtures are thought to provide a more balanced diet for detritivores (Epps et al. 2007). This effect has been often attributed to the elemental and structural differences between litter species (Schimel and Hättenschwiler 2007, Gessner et al. 2010).

Despite the importance of complementarity effects under ambient rainfall, dominance mechanisms increased in relative importance under altered rainfall. In particular, under HA rainfall, E. uniflora litter had a positive dominance effect, such that bromeliads that included this species had higher total decomposition. We suspect that this is due to the disruption of oviposition cues under extreme rainfall which allowed bromeliads with the less palatable litter species (Cyperus sp. and C. hilariana) to attract detritivores. Only if such litter mixtures with high detrital abundances additionally contained the palatable $E$. uniflora could high rates of litter decomposition occur, leading to a positive diversity-decomposition relationship conditional on E. uniflora presence (i.e., positive dominance). Indeed, only in the HA rainfall scenario where we observed positive dominance was there a positive association between detritivore density and the rate of E. uniflora decomposition. This positive dominance mechanism did not operate under ambient conditions, as there detritivore densities accurately tracked the palatability of the litter species. This shift from complementarity to dominance effects in disturbed conditions is predicted by insurance theory but is not supported by studies on living plants (Mulder et al. 2001, Steudel et al. 2011, Wang et al. 2013, Craven et al. 2016, Wright et al. 2017). We suggest that such studies on living plant diversity are difficult to compare to studies of litter diversity, such as ours. For example, in living plant communities, the importance of facilitation for plant communities has been well documented to increase with climatic stress (Callaway et al. 2002), so it is not surprising that facilitation also plays a greater role in driving biodiversity-function effects under stress in some studies (Mulder et al. 2001, Wang et al. 2013, Wright et al. 2017). However, decomposition of dead plant material is fundamentally different than the production of live biomass, in that litter does not compete for resources to maximize fitness. Decomposition instead results from the action of other species (i.e., microbes, invertebrates) on the litter.

Altered rainfall scenarios also had negative dominance effects, associated with Clusia hilariana litter; bromeliads that included this species had overall lower decomposition than expected from monocultures. Although it is not clear what mechanism is responsible for this negative dominance under intermediate changes in rainfall, we do note that a study of terrestrial decomposition also reported that drought resulted in increasing numbers of antagonistic (mixtures less than expected from monoculture) interactions between litter species (Santonja et al. 2015). In that study, the authors suggested that synergistic relationships develop slowly over time, as secondary metabolites are leached from the litter, allowing the nutritional complementarity between litter to determine decomposition; drought presumably reduces the rate of leaching, disrupting the development of 
these synergistic effects. Clusia hilariana litter is a particularly tough and waxy functional group that requires substantial microbial conditioning to be processed by invertebrates (Dias et al. 2006). Microbial productivity declined as rainfall became both more clustered and intense, reducing the potential for such litter conditioning. In general, microbial conditioning of organic matter is an important prerequisite for detritivore decomposition (Vogel et al. 2013).

The final way in which litter diversity and rainfall interacted was through non-additive effects on the magnitude of ecosystem processes. Specifically, methane concentration in the water within bromeliad tanks increased with litter diversity, but only under ambient rainfall. Under altered rainfall, methane concentrations were low regardless of litter diversity. Methane, an important greenhouse gas, is produced by the microbial decomposition of organic matter under anoxic conditions. We suggest that under ambient conditions, the high decomposition rates associated with diverse litter mixtures could result in methane production because microbial productivity was high and water likely persistent, leading to anoxia. As rainfall events became increasingly clustered and high amplitude, we found that microbial productivity dropped and drought was likely more prevalent, preventing decomposition from fueling methanogenesis. Although our experiment was only able to show how rainfall affected the association between decomposition, microbial production, and methane, future experiments could corroborate this mechanism by directly manipulating the microbial community or detrital amounts. Negative effects of drought on microbial activity have been already documented in previous studies using tank bromeliad ecosystems (Brandt et al. 2015, Marino et al. 2017), as well as in streams and soils (Bruder et al. 2011, Vogel et al. 2013). Given that methane is a greenhouse gas, this suggests a potential negative feedback whereby increased prevalence of drought reduces methane emissions. This feedback should be broadly relevant for shallow aquatic ecosystems subject to droughts. For example, lower methane emissions are also observed in rice paddies and wetlands following drought (Altor and Mitsch 2008, Green et al. 2017). An important question for future research is to what degree this negative drought-methane feedback offsets the previously established positive feedback between warming and methane production (van Nes et al. 2015).

In sum, we have concluded that altered rainfall interacts with diminished litter diversity to affect three aspects of ecosystem functions: their stability, the underlying mechanisms, and non-additivity in response. Such interdependencies between drivers of global change have recently been highlighted as key to predicting planetary state changes (Hughes et al. 2013). However, it has generally been unappreciated the many different ways that such interdependencies may occur. For example, although a multiple-stressor approach is now increasingly applied to climate change studies, such approaches generally only consider whether stressors have non-additive effects on the responses (Scheffer et al. 2015). However, it is quite possible for climate change to increase the variance of processes without affecting the mean, and so to have insurance effects of diversity in the absence of non-additive effects (Pires et al. 2018). In many cases, such deviations in ecosystem properties are of concern, and so assessments of insurance effects provide valuable guidance for climate mitigation policies (Nelson et al. 2013). Finally, we show that, although rainfall does not affect the pattern between litter diversity and decomposition, it affects the process. The increasing reliance of decomposition on a specific litter species on suggests a growing fragility in the system. Our experiment is one of the first from the tropics to explore multiple aspects of how ecosystem properties will be impacted by concurrent biodiversity loss and climate change. The results of our study underline the importance of coupling both major drivers of global change to determine the ecological functions in the coming years.

\section{ACKNOWLEDGMENTS}

We are grateful to V. Dib, J. Leal, and S. Jacques for field and lab assistance and to J. Cronin and two anonymous reviewers for their comments on the manuscript. This work was part of a project titled "Impact of Global Climate Changes on Tropical Continental Aquatic Ecosystems" supported by grants from CENPES/PETROBRAS (ANPETRO 9803 to V. F. Farjalla). In addition, A. P. F. Pires, V. F. Farjalla, and D. S. Srivastava collaborated on the analysis and writing of this manuscript thanks to the Canada-Brazil Awards Joint Research Project program co-run by the Department of Foreign Affairs (Canada) and CAPES (Brazil). A. P. F. Pires and N. A. C. MacDonald are grateful to CNPq and CAPES for their postgraduate scholarships. D.S.S. further acknowledges support from the Natural Sciences and Engineering Council of Canada. V. F. Farjalla is partially supported by $\mathrm{CNPq}$ productivity grants. This paper is also a contribution of the Brazilian Research Network on Global Climate Change, FINEP/Rede CLIMA Grant Number 01.13.0353-00.

\section{Literature Cited}

Altor, A. E., and W. J. Mitsch. 2008. Pulsing hydrology, methane emissions and carbon dioxide fluxes in created marshes: a 2-year ecosystem study. Wetlands 28:423-438.

Amundrud, S. L., and D. S. Srivastava. 2015. Drought sensitivity predicts habitat size sensitivity in an aquatic ecosystem. Ecology 96:1957-1965.

Awasthi, A., M. Singh, S. K. Soni, R. Singh, and A. Kalra. 2014. Biodiversity acts as insurance of productivity of bacterial communities under abiotic perturbations. ISME Journal 8:2445-2452.

Behl, S., and H. Stibor. 2015. Prey diversity and prey identity affect herbivore performance on different time scales in a long term aquatic food-web experiment. Oikos 124:1192-1202.

Brandt, F. B., G. O. Martinson, B. Pommerenke, J. Pump, and R. Conrad. 2015. Drying effects on archaeal community composition and methanogenesis in bromeliad tanks. FEMS Microbiology Ecology 91:1-10.

Bruder, A., E. Chauvet, and M. O. Gessner. 2011. Litter diversity, fungal decomposers and litter decomposition under simulated stream intermittency. Functional Ecology 25:1269-1277.

Callaway, R. M., et al. 2002. Positive interactions among alpine plants increase with stress. Nature 417:844-848.

Cogliatti-Carvalho, L., A. F. de Freitas, C. F. da Rocha, and M. V. Sluys. 2001. Variation in structure and composition of Bromeliaceae at five zones of "restinga" in Jurubatiba National Park, Macae, RJ. Brazilian Journal of Botany 24:1-9.

Craven, D., et al. 2016. Plant diversity effects on grassland productivity are robust to both nutrient enrichment and drought. Philosophical Transactions of the Royal Society B 371:20150277. 
Dias, A. T. C., E. A. de Mattos, S. A. Vieira, J. V. Azeredo, and F. R. Scarano. 2006. Aboveground biomass stock of native woodland on a Brazilian sandy coastal plain: estimates based on the dominant tree species. Forest Ecology and Management 226: 364-367.

Duarte, S., C. Pascoal, and F. Cássio. 2009. Functional stability of stream-dwelling microbial decomposers exposed to copper and zinc stress. Freshwater Biology 54:1683-1691.

Eklöf, J. S., C. Alsterberg, J. N. Havenhand, K. Sundbäck, H. L. Wood, and L. Gamfeldt. 2012. Experimental climate change weakens the insurance effect of biodiversity. Ecology Letters 15:864-872.

Epps, K. Y., N. B. Comerford, J. B. Reeves, W. P. Cropper, and Q. R. Araujo. 2007. Chemical diversity-highlighting a species richness and ecosystem function disconnect. Oikos 116:18311840.

Farjalla, V. F., D. S. Srivastava, N. A. C. Marino, F. D. Azevedo, V. Dib, P. M. Lopes, A. S. Rosado, R. L. Bozelli, and F. A. Esteves 2012. Ecological determinism increases with organism size. Ecology 93:1752-1759.

Farjalla, V. F., A. L. González, R. Céréghino, O. Dézerald, N. A. C. Marino, G. C. O. Piccoli, B. A. Richardson, M. J. Richardson, G. Q. Romero, and D. S. Srivastava. 2016. Terrestrial support of aquatic food webs depends on light inputs: a geographically-replicated test using tank bromeliads. Ecology 97:2147-2156.

Fox, J. W. 2005. Interpreting the "selection effect" of biodiversity on ecosystem function. Ecology Letters 8:846-856.

Gessner, M. O., C. M. Swan, C. K. Dang, B. G. McKie, R. D. Bardgett, D. H. Wall, and S. Hättenschwiler. 2010. Diversity meets decomposition. Trends in Ecology and Evolution 25:372-380.

Green, A. J., et al. 2017. Creating a safe operating space for wetlands in a changing climate. Frontiers in Ecology and the Environment 15:1-9.

Hammill, E., T. B. Atwood, and D. S. Srivastava. 2015. Predation threat alters composition and functioning of bromeliad ecosystems. Ecosystems 18:857-866.

Haubrich, C. S., A. P. F. Pires, F. A. Esteves, and V. F. Farjalla 2009. Bottom-up regulation of bacterial growth in tropical phytotelm bromeliads. Hydrobiologia 632:347-353.

Hillebrand, H., and B. Matthiessen. 2009. Biodiversity in a complex world: consolidation and progress in functional biodiversity research. Ecology Letters 12:1405-1419.

Hooper, D. U., E. C. Adair, B. J. Cardinale, J. E. K. Byrnes, B. A Hungate, K. L. Matulich, A. Gonzalez, J. E. Duffy, L. Gamfeldt, and M. I. O'Connor. 2012. A global synthesis reveals biodiversity loss as a major driver of ecosystem change. Nature 486:105-108.

Hoorens, B., R. Aerts, and M. Stroetenga. 2003. Does initial litter chemistry explain litter mixture effects on decomposition? Oecologia 137:578-586

Hughes, T. P., S. Carpenter, J. Rockström, M. Scheffer, and B. Walker. 2013. Multiscale regime shifts and planetary boundaries. Trends in Ecology and Evolution 28:389-395.

IPCC. 2014. Climate change 2013: the physical science basis. Intergovernmental Panel on Climate Change. Cambridge University Press, Cambridge, UK.

Isbell, F., et al. 2015. Biodiversity increases the resistance of ecosystem productivity to climate extremes. Nature 526:574-577.

Jentsch, A., et al. 2011. Climate extremes initiate ecosystem-regulating functions while maintaining productivity. Journal of Ecology 99:689-702.

Kominoski, J. S., T. J. Hoellein, J. J. Kelly, and C. M. Pringle. 2009. Does mixing litter of different qualities alter stream microbial diversity and functioning on individual litter species? Oikos 118:457-463.

Leroy, C., B. Corbara, O. Dézerald, M. K. Trzcinski, J. F. Carrias, A. Dejean, and R. Céréghino. 2017. What drives detrital decomposition in neotropical tank bromeliads? Hydrobiologia 802: $85-95$.

Loreau, M., and A. Hector. 2001. Partitioning selection and complementarity in biodiversity experiments. Nature 412:72-76.
Louca, S., S. M. S. Jacques, A. P. F. Pires, J. S. Leal, D. S. Srivastava, L. W. Parfrey, V. F. Farjalla, and M. Doebeli. 2016. High taxonomic variability despite stable functional structure across microbial communities. Nature Ecology and Evolution 1:15

Louca, S., S. M. S. Jacques, A. P. F. Pires, J. S. Leal, A. L. González, M. Doebeli, and V. F. Farjalla. 2017. Functional structure of the bromeliad tank microbiome is strongly shaped by local geochemical conditions. Environmental Microbiology 19:3132-3151.

Marengo, J. A., T. Ambrizzi, R. P. da Rocha, L. M. Alves, S. V. Cuadra, M. C. Valverde, R. R. Torres, D. C. Santos, and S. E. T. Ferraz. 2010. Future change of climate in South America in the late twenty-first century: intercomparison of scenarios from three regional climate models. Climate Dynamics 35:1073-1097.

Marino, N. A. C., D. S. Srivastava, A. A. M. MacDonald, J. S. Leal, A. B. A. Campos, and V. F. Farjalla. 2017. Rainfall and hydrological stability alter the impact of top predators on food web structure and function. Global Change Biology 23:673-685.

Martinson, G. O., F. A. Werner, C. Scherber, R. Conrad, M. D. Corre, H. Flessa, K. Wolf, M. Klose, S. R. Gradstein, and E. Veldkamp. 2010. Methane emissions from tank bromeliads in neotropical forests. Nature Geoscience 3:766-769.

Mulder, C. P., D. D. Uliassi, and D. F. Doak. 2001. Physical stress and diversity-productivity relationships: the role of positive interactions. Proceedings of the National Academy of Sciences USA 98:6704-6708.

Nelson, E. J., et al. 2013. Climate change's impact on key ecosystem services and the human well-being they support in the US. Frontiers in Ecology and the Environment 11:483-493.

Pires, A. P. F., N. A. C. Marino, D. S. Srivastava, and V. F. Farjalla. 2016. Predicted rainfall changes disrupt trophic interactions in a tropical aquatic ecosystem. Ecology 97:2750-2759.

Pires, A. P. F., J. da Silva Leal, and E. T. H. M. Peeters. 2017. Rainfall changes affect the algae dominance in tank bromeliad ecosystems. PLoS ONE 12:e0175436.

Pires, A. P. F., D. S. Srivastava, and V. F. Farjalla. 2018. Is biodiversity able to buffer ecosystems from climate change? What we know and what we don't. BioScience https://doi.org/10.1093/ biosci/biy013/4913799

R Development Core Team. 2015. R: a language and environment for statistical computing. R Foundation for Statistical Computing, Vienna, Austria. www.r-project.org

Santonja, M., C. Fernandez, T. Gauquelin, and V. Baldy. 2015. Climate change effects on litter decomposition: intensive drought leads to a strong decrease of litter mixture interactions. Plant and Soil 393:69-82.

Scheffer, M., et al. 2015. Creating a safe operating space for iconic ecosystems. Science 347:1317-1319.

Schimel, J. P., and S. Hättenschwiler. 2007. Nitrogen transfer between decomposing leaves of different $\mathrm{N}$ status. Soil Biology and Biochemistry 39:1428-1436.

Srivastava, D. S. 2006. Habitat structure, trophic structure and ecosystem function: interactive effects in a bromeliad-insect community. Oecologia 149:493-504.

Steudel, B., Y. Hautier, A. Hector, and M. Kessler. 2011. Diverse marsh plant communities are more consistently productive across a range of different environmental conditions through functional complementarity. Journal of Applied Ecology 48:1117-1124.

Steudel, B., A. Hector, T. Friedl, C. Löfke, M. Lorenz, M. Wesche, M. Kessler, and M. O. Gessner. 2012. Biodiversity effects on ecosystem functioning change along environmental stress gradients. Ecology Letters 15:1397-1405.

Tilman, D. 1996. Biodiversity: population versus ecosystem stability. Ecology 77:350-363.

van Meeteren, M. J. M., A. Tietema, E. E. van Loon, and J. M. Verstraten. 2008. Microbial dynamics and litter decomposition under a changed climate in a Dutch heathland. Applied Soil Ecology 38:119-127.

van Nes, E. H., M. Scheffer, V. Brovkin, T. M. Lenton, H. Ye, E. Deyle, and G. Sugihara. 2015. Causal feedbacks in climate change. Nature Climate Change 5:3-6. 
Vogel, A., N. Eisenhauer, A. Weigelt, and M. Scherer-Lorenzen. 2013. Plant diversity does not buffer drought effects on earlystage litter mass loss rates and microbial properties. Global Change Biology 19:2795-2803.

Wang, Y., S. Yu, and J. Wang. 2007. Biomass-dependent susceptibility to drought in experimental grassland communities. Ecology Letters 10:401-410.

Wang, J., C. B. Zhang, T. Chen, and W. H. Li. 2013. From selection to complementarity: the shift along the abiotic stress gradient in a controlled biodiversity experiment. Oecologia 171:227-235.
Wright, A. J., D. A. Wardle, R. Callaway, and A. Gaxiola. 2017. The overlooked role of facilitation in biodiversity experiments. Trends in Ecology and Evolution 32:383-390.

Yachi, S., and M. Loreau. 1999. Biodiversity and ecosystem productivity in a fluctuating environment: the insurance hypothesis. Proceedings of the National Academy of Sciences USA 96: $1463-1468$.

Zotz, G., and V. Thomas. 1999. How much water is in the tank? Model calculations for two epiphytic bromeliads. Annals of Botany 83:183-192.

\section{SUPPORTING INFORMATION}

Additional supporting information may be found in the online version of this article at http://onlinelibrary.wiley.com/doi/10.1002/ecy. 2202/suppinfo

\section{Data Availability}

Data associated with this study is available from Dryad Digital Repository: https://doi.org/10.5061/dryad.58g2t4k 